\title{
BAD EVOLUTION OF A CONGENITAL TORTICOLLIS. CASE REPORT.
}

Andrés Rodriguez Salvador¹, Miguel David Membrilla Mesa¹, Gabriela Espigares Correa ${ }^{1}$, Rocío Pozuelo Calvo ${ }^{1}$, Almudena Serrano ${ }^{1}$, Inmaculada García Montes ${ }^{1}$

1 Physical Medicine and Rehabilitation Department. Hospital Universitario Virgen de las Nieves, Granada, Spain.

Introduction: Congenital torticollis is an adquired
cefalic inclination and rotation of the neck due to
different causes, most of them benign (muscular congenit
torticollis and postural torticollis).
In all cases, it is necessary to make a differential
diagnose with more severe pathologies of the infant
when the rotation and inclination of the neck do not
recover.

Purpose: We present a case report to show the importance of the follow up and the complementary images to reach a diagnose when a congenital torticollis does not respond to the physical therapy.
Results: The patient was sent to Neurosurgery Department and we are following him closely during his first 3 years of life to guarantee a detection of any complication on his development.

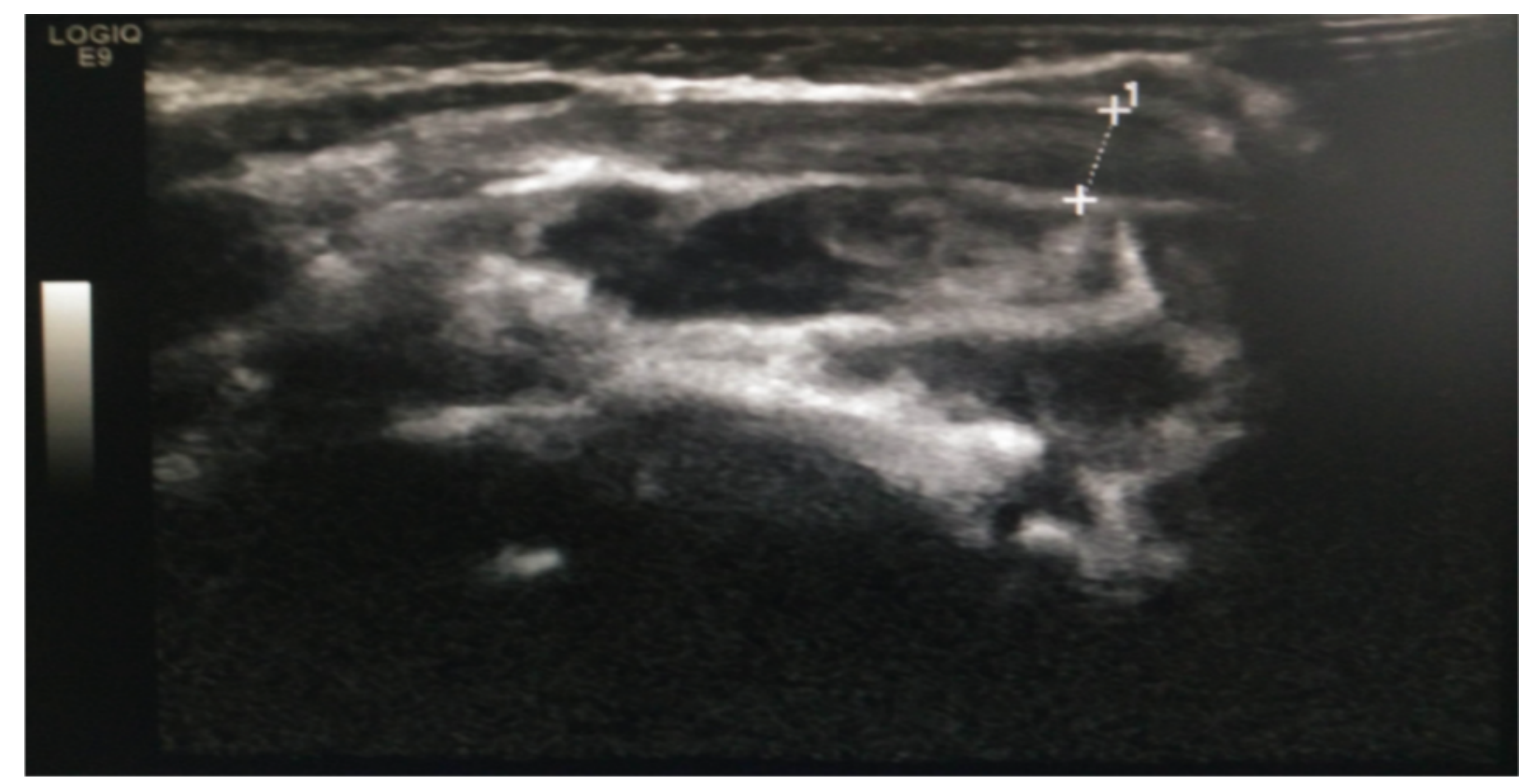

Illustration 1

Conclusions: An exhaustive physical examination and a correct following of infants with apparently benign muscular congenital torticollis, is needed to detect subyacent pathologies and further complications, as shown in our case report.

\section{Bibliography:}

I. Wang $S^{\prime}, L^{\prime} J^{\prime}$, Lu G', Wang B', Wang $X^{2}$. Cervical hemivertebra resection and torticollis correction report on two cases and literature review. Eur J 2018 Feb 28.

2. Kapetanakis $S^{\prime}$, Gkasdaris $G^{\prime}$, Nastoulis $E^{2}$, Stayrev $V^{3}$. Hemivertebra of the cervical spine: an uncommon background for neck pain, cervical scoliosis, and torticollis. Clin Case Rep. 2017 Aug 22;5(10): 1718-1719

3. Raco $A^{\prime}$, Raimondi AJ, De Ponte FS, Brunelli $A$ Bristot $R$, Bottini $D j$, lanettí $G$. Congenital torticollis in association with craniosynostosis. Childs Nerv Syst. 1999 Apr; 15 (4): I63-168 